\title{
FORMULATION AND EVALUATION OF CURCUMIN LOADED LIPOSOME AND ITS BIO-ENHANCEMENT
}

\author{
Khushboo Verma, Jhakeshwar Prasad*, Suman Saha, Surabhi Sahu
}

Department of Pharmaceutics, Columbia Institute of Pharmacy, Vill-Tekari, Near Vidhansabha, Raipur, Chhattisgarh, India Chhattisgarh Swami Vivekanand Technical University (CSVTU), Bhilai, Chhattisgarh

\begin{abstract}
The aim of this work was to develop and evaluate curcumin loaded liposome and its bio- enhancement. Curcumin was selected as a natural drug for liposome formulation. Curcumin show variety of biological activity but it also shows poor bioavailability due to low aqueous solubility (1 $\mu \mathrm{g} / \mathrm{ml}$ ), poor absorption and rapid metabolism so that piperine was selected as bio enhancer to improve curcumin bioavailability. Soy lecithin and cholesterol were used to prepared curcumin and curcumin-piperine loaded liposome at different ratio by thin film hydration method because of easy to perform, and high encapsulation rates of lipid. The all liposome formulations (F1-F5) were evaluated by mean particle size, polydispersity index, zeta potential, encapsulation efficiency and drug release. Bioavailability was also determined on rat. Blood samples were collected at specific intervals, and plasma was separated by ultracentrifugation. Plasma was analyzed by high-performance liquid chromatography at $425 \mathrm{~nm}$ taking acetonitrile: water (75:25 v/v) acidified with $2 \%$ acetic acid as a mobile phase at a flow rate of $0.5 \mathrm{ml} / \mathrm{min}$ using C18 column. The mean particle size was found in the range between 800-1100 that indicate liposome are large unilamellar vesical types. By zeta potential study its conform that the all formulation was stable. The encapsulation efficiency of all liposome formulation are varied between $59-67 \%$. In vitro drug release was analyse in $7.4 \mathrm{pH}$ phosphate buffer, the maximum \%CDR observed at the 12 hrs., and formulation are follow sustained release thus they reduce metabolism, good absorption rate which improve bioavailability of drug. From in-vivo study, it is clear that curcumin-piperine liposomal formulation, increases $\mathrm{Cmax}$, area under the curve, and mean residence time significantly as compared to pure curcumin and pure curcumin liposome.
\end{abstract}

Keywords: liposome; Curcumin; Piperine, Thin film hydration method; Bioavailability

Article Info: Received 10 July 2019; $\quad$ Review Completed 17 Aug 2019; Accepted 23 Aug 2019; Available online 30 Aug 2019

Cite this article as:

Verma K, Prasad J, Saha S, Sahu S, Formulation and Evaluation of Curcumin Loaded Liposome and its Bio-Enhancement, Journal of Drug Delivery and Therapeutics. 2019; 9(4-A):425-427 http://dx.doi.org/10.22270/jddt.v9i4-A.3505

*Address for Correspondence:

Jhakeshwar Prasad, Columbia Institute of Pharmacy, Vill-Tekari, Near Vidhansabha, Raipur, Chhattisgarh, India

\section{INTRODUCTION:}

Turmeric are a one of most popular pant that contains various medical properties. Turmeric is also known as "Indian saffron." Modern medicine has begun to recognize its importance, as indicated by the over 3000 publications dealing with turmeric that came out within the last 25 years. It is very popular in spices category as a food product Directorate of Canada, and joint Expert Committee of the food and agriculture organization/World health Organization (FAO/WHO) $(\mathbf{1 , 2})$.

Curcumin (Diferuloylmethane) are the main constituent of spices turmeric and is obtain from the rhizome of the East Indian plant Curcuma longa, family- Zingiberacae. It is one on the most promising natural products for both the biological and chemical study (3). Polyphenols have capacity to prevent and treatment of various disease due to their antioxidant capabilities (4). Polyphenols are derived from many components of the human food like turmeric.
Curcumin has not only food derivatives it also shown multiple beneficial medicine properties to prevent the disease (5).

Curcumin belong to Curcuminoids group, which are hydrophobic, low molecular weight polyphenol responsible for yellow color of turmeric $(6,7)$. Curcumin having various functional group, the aromatic ring (phenol) are connected with two $\alpha, \beta$-unsaturated carbonyl groups. Molecular configuration of curcumin can exist in bis-keto and enolate of tautomeric forms $(\mathbf{8 , 9 , 1 0 )}$.<smiles>COc1cc(/C=C/C(=O)/C=C(O)/C=C/c2ccc(O)c(OC)c2)ccc1O</smiles>

Fig. 1: Structure of curcumin 
Many researches has been proven that, the reasons for poor bioavailability of any drug are correlated to poor absorption, high rate of metabolism, rapid elimination and clearance from the body. The only one major drawback of curcumin is poor oral bioavailability due to low aqueous solubility (1 $\mu \mathrm{g} / \mathrm{ml}$ ), poor absorption and rapid metabolism. When the curcumin is taken orally only small portion is absorbed within the intestine and this absorbed curcumin has rapid metabolism in the liver and plasma and major portion is excreted through the faces and urine by converted to glucuronides and sulfates (water-soluble) metabolites $(11,12,13,14,15)$.

In this case some of the possible ways to overcome these problems, Adjutants which can block metabolic pathways of curcumin, are one of the major means that are being used to improve its bioavailability. Nanoparticles, liposomes, micelles, and phospholipid complexes are other promising novel formulations, which appear to provide longer circulation, better permeability, and resistance to metabolic processes (12).

\section{MATERIALS AND METHODS:}

Soy lecithin was purchased from Hi Media Laboratories Pvt. Ltd, Mumbai, India. Cholesterol, Methanol, Petroleum ether,Glacial acetic acid and Sodium chloridewas purchased from Loba Chemie Pvt. Ltd, Mumbai, India. Curcumin and Piperine was purchased from Alfa Aesar, Hyderabad, India. Chloroform, Acetic acid HPLC grade, Acetonitrile HPLC grade and Water for HPLCwas purchased from Merck life Science Private Ltd., Mumbai, India.Potassium di hydrogen phosphatewas purchased from Molychem, Mumbai, India.

\section{Preformulation Studies}

\section{Physical appearance:}

Physical appearance of any substance was analyzed on the bases of size, shape and appearance by visually inspection and compare with standard. The usual appearance of curcumin and piperine was deals with Indian pharmacopeia standard (16)

\section{Melting point:}

The melting point of curcumin and piperine was determine by using digital melting point apparatus (Rolex, Haryana) by taken a small amount of drug in capillary tube closed by one side and placed in the apparatus. Then noted the temperature at which drug sample get completely melted and disappeared (17).

\section{Solubility study:}

The solubility of curcumin and piperine was determine by taking a fixed and small amount of solute with added fixed amount of solvent in a test tube, after addition of solvent test tube was vigorously shaken for dissolve solute particles. The solubility of the curcumin was tested in various solvents including water, methanol, chloroform, petroleum ether, glacial acetic acid, acetic acid, ethanol etc. The solubility was observed only by the visual inspection $(\mathbf{1 8 , 1 9 )}$.

\section{Compatibility test by FT-IR spectral studies:}

Compatibility test was performed by Fourier Transform Infrared Spectrophotometer (FTIR). For the FT-IR (Shimadzu, Japan) study first blank disc was prepared with potassium bromide $(\mathrm{KBr})$ which placed in the path of the reference beam. Scanned it at the scanning range between $4000 \mathrm{~cm}^{-1}$ and $450 \mathrm{~cm}^{-1}$, resolution was $1 \mathrm{~cm}^{-1}$ and then analysis pure drug and drug-excipient (physical mixture) was taken and drying properly to remove moisture and grounded with potassium bromide $(\mathrm{KBr})$ (1:1000 ratio) then placed in sample holder. Obtained peak were interpreted by functional group if any change in peak of functional group as compared to pure drug peak will indicate that interaction of drug-excipient or drug-polymer (20, 21).

\section{Determination of $\lambda$ max:}

UV spectrophotometer (Shimadzu-1800, Japan) was used to determine the maximum absorption $(\lambda \max )$ of drug. Stock solution of Curcumin and piperine was prepared in methanol solvent, the solution has containing $2 \mu \mathrm{g} / \mathrm{ml}$ were scanned separately in the range between $300-500 \mathrm{~nm}$ to determine the wavelength of maximum absorption of drug $(22,23)$.

\section{Development of calibration curve}

Calibration curve of curcumin and piperine was developed by UV-visible spectrophotometer.

\section{Preparation of stock solution:}

A stock solution of curcumin and piperine was prepared by dissolving $50 \mathrm{mg}$ of drug in $50 \mathrm{ml}$ of methanol in volumetric flask to obtain a concentration of $1 \mathrm{mg} / \mathrm{ml}$. Selection of solvent system was based on the solubility and stability of drug in solvent. $5 \mathrm{ml}$ of this solution was further diluted with $50 \mathrm{ml}$ of same solvent (methanol) to get the final concentration of $100 \mu \mathrm{g} / \mathrm{ml}$ and this was used as the standard stock solution.

\section{Preparation of calibration curve:}

From this stock solution various dilutions were made to obtain of $1,2,3,4,5$, and $6 \mu \mathrm{g} / \mathrm{ml}$ concentration in volumetric flak in a same solvent. And then absorbance values of these solutions were measure at lambda max $425 \mathrm{~nm}(24,25)$

\section{Preparation of liposome:}

Curcumin and curcumin-piperine loaded liposomes were prepared by the thin film hydration method. Required amount of drug $(200 \mathrm{mg})$, soy lecithin $(500 \mathrm{mg})$, and cholesterol $(500 \mathrm{mg}$ ) were dissolve in methanol: chloroform solvent (1:9), the dried ingredient was dissolve in solvent by hand shaking method in round bottom flask. And solution was dried by hand shaking to form a thin film of lipid. The flask was kept overnight for complete evaporation of organic solvents. Then the dried layer was hydrated with $30 \mathrm{ml}$ of distilled water and vortexed for 1 hours. After hydration liposomal suspension was formed. Finally, the product obtained is collected and stored in a sealed container at 2$8^{\circ} \mathrm{C}$ until analysis (26). 
Table 1: Formulation table

\begin{tabular}{|c|c|c|c|c|c|c|}
\hline \multirow[t]{3}{*}{ S.No. } & \multirow[t]{3}{*}{ Ingredient } & \multicolumn{5}{|c|}{ Quantity } \\
\hline & & \multicolumn{5}{|c|}{ Formulation cord } \\
\hline & & F1 & F2 & F3 & F4 & F5 \\
\hline 1 & Curcumin(mg) & 200 & & & & \\
\hline 2 & Curcumin: Piperine (mg) (w/w) & & $(5: 1) 200$ & $(10: 1) \quad 200$ & $(15: 1) 200$ & $(20: 1) 200$ \\
\hline 3 & Soy Lecithin (mg) & 500 & 500 & 500 & 500 & 500 \\
\hline 4 & Cholesterol (mg) & 500 & 500 & 500 & 500 & 500 \\
\hline 5 & Methanol : Chloroform (v/v) & 1:9 q.s. & 1:9 q.s. & 1:9 q.s. & 1:9 q.s. & 1:9 q.s. \\
\hline 6 & Distilled water & $30 \mathrm{ml}$ & $30 \mathrm{ml}$ & $30 \mathrm{ml}$ & $30 \mathrm{ml}$ & $30 \mathrm{ml}$ \\
\hline
\end{tabular}

\section{Evaluation/characterization of formulated liposome}

\section{Particle size and polydispersity index estimation:}

Mean particle size and polydispersity index of prepared liposomes were estimated using Zetasizer 300HSA (Malvern instrument, Malvern, UK). The sample are diluted with distilled water and analyzed at $25^{\circ} \mathrm{C}$ using quartz micro cuvette then run the instrument and estimated the particle size and polydispersity index $(27,29)$.

\section{Zeta potential:}

Zeta potential was analyze by using Zetasizer. The formulations were diluted to 1:1000 with the aqueous phase of the formulation to get a suitable kilo counts per second (kcps). Analysis was carried out at $25^{\circ} \mathrm{C}$ with an angle of detection of $90^{\circ}(27,28)$.

\section{Drug encapsulation efficiency:}

The percentage drug entrapped (PDE) in the Curcumin and curcumin-piperine loaded liposomes was determined by the ultra-centrifugation at $11000-15000 \mathrm{rpm}$ for $45 \mathrm{~min}$ in an ultracentrifuge to septet the loaded drug from free drug. Then, supernatant was separated and analyzed after suitable dilution in solvent by UV-Visible spectrophotometer at $425 \mathrm{~nm}$, which is indicates the amount of free drug. The liposome(sediment) was redispersed in same solvent (methanol) and analyzed drug content after dilution using UV-visible spectrophotometer, which is indicate the amount of drug entrapped $(\mathbf{3 0 , 3 1 )}$.

The entrapment efficiency of liposome was calculated by this equation

$$
\mathrm{DEE}=[(\mathrm{T}-\mathrm{C}) / \mathrm{T}] \times 100
$$

Where,

$\mathrm{T}=$ total amount of drug that is detected both in the supernatant and sediment,

$\mathrm{C}=$ amount of drug detected only in the supernatant.

\section{In vitro drug release studies:}

In vitro drug release was performed using dialysis membrane method. Firstly, membrane was clamped in open glass tube for drug release and consider as a donor compartment.7.4 $\mathrm{p}^{\mathrm{H}}$ Phosphate buffer solution (PBS) $200 \mathrm{ml}$ was used as dissolution medium and taken in receiver compartment.

The glass tube (donor compartment) edge was just touched in receiver compartment. Before the release test, $0.5 \mathrm{ml}$ of formulation was diluted with $3 \mathrm{ml}$ of dissolution medium and placed into glass tube and maintains the temperature $37^{\circ} \mathrm{C}$ at $100 \mathrm{rpm}$ by magnetic stirrer and bead. $5 \mathrm{ml}$ sample was withdrawing from receiver compartment at fixed intervals and maintain the sink condition by replaced with fresh medium immediately. Sample were analyzed using UV-
Visible Spectrophotometer at $425 \mathrm{~nm}$. Drug release was checked for 12 hrs. (32).

\section{In vivo drug release (Pharmacokinetic study for determination of Curcumin):}

In vivo study was perform in Sprague-Dawley rat. All the animal experiments were performed according to the rules and guidelines of the committee for the purpose of control and supervisions of experiments on animals (CPCSEA). This study was approved by Institutional Animal Ethical committee Regd.No.1321/PO/ReBi/S/10/CPCSEA, Date22/10/014, Approval No. CIP/IAEC/2017/099 (33).

\section{Construction of Curcumin standard graph:}

A standard graph of Curcumin was developed for the assessment of pharmacokinetics of the Curcumin formulations in rat by the following method. $100 \mathrm{mg}$ of pure Curcumin was dissolved in $100 \mathrm{ml}$ of methanol and sonicated for $10 \mathrm{~min}$ to prepare stock solution. $10 \mathrm{ml}$ stock solution was taken and diluted with the same solvent, i.e., methanol up to $100 \mathrm{ml}$ and again sonicated to form standard solution. From standard solution, further dilution was prepared, viz., $0.2 \mathrm{ml}$ was transferred from the standard solution into test tubes and diluted to $10 \mathrm{ml}$ with methanol to form $2 \mu \mathrm{g} / \mathrm{ml}$. The solutions so prepared $(2,4,6,8$, and 10 $\mu \mathrm{g} / \mathrm{ml}$ ). The samples were analyzed in HPLC at $425 \mathrm{~nm}$ taking acetonitrile: water (75:25 v/v) acidified with $2 \%$ acetic acid as a mobile phase at a flow rate of $0.5 \mathrm{ml} / \mathrm{min}$ using C18 column (31). The retention time and peak area were noted and data obtained through HPLC analysis was further used to interpolate, the experimental peak area values to get the corresponding concentration of Curcumin in plasma.

\section{Procedure:}

1. Selection of experimental animal

2. Grouping of animal

3. Administration of formulation into animal

4. Collection of blood sample

5. Determination of drug sample in animal by HPLC method and determination of pharmacokinetic parameter such as - $\mathrm{C}_{\max }, \mathrm{T}_{\max }, \mathrm{AUC}$, MRT, Kel

Animals were divided into four groups; each group contains six rats:

Group 1 received: Liposomal Curcumin

Group 2 received: Liposomal Curcumin + pure piperine

Group 3 received: Liposomal Curcumin: Piperine formulation

Group 4 (standard) received: Pure Curcumin.

Blood samples $(0.5 \mathrm{ml})$ from the experimental rats were collected by retro-orbital plexus technique into a sequence 
of micro centrifuge tubes containing $0.3 \mathrm{ml}$ of sodium citrate solution. Blood samples were taken at different time intervals such as $30 \mathrm{~min}, 1,2,3,6,12,18$, and $24 \mathrm{~h}$. The collected blood samples were centrifuged at a speed of 5000 rpm for $10 \mathrm{~min}$, and plasma was separated into an additional micro centrifuge tube using micropipette and stored in deep freeze until analysis. The drug was extracted out from plasma by adding in a methanolic solvent, and it was centrifuged for $10 \mathrm{~min}$ from which the organic layer of drug comes out other than sediment. The organic layer of drug was then injected into the HPLC system for the further processing of determination of plasma drug concentration and other parameters, i.e., area under the curve (AUC), Cmax, etc. and report the bioavailability enhancement of curcumin $(34,35,36,37)$.

\section{RESULTS}

\section{Preformulation studies}

\section{Physical appearance:}

Physical appearance of Curcumin and piperine was deals with IP. Curcumin was found to be bright yellow orange amorphous powder and piperine was found to be pale yellow crystal.

\section{Determination of melting point:}

Melting point of Curcumin was found to be in range between $180-183{ }^{\circ} \mathrm{C}$ and piperine was found to be $130{ }^{\circ} \mathrm{C}$ which compiles with Indian pharmacopoeia specification so it was confirmed that the sample which purchased for liposome was Curcumin and piperine. The melting data show in table 2.

Table 2: Melting point of Curcumin and piperine

\begin{tabular}{|c|c|c|c|}
\hline S.No. & Drug & Melting point (Theoretical) & Average melting point(practically) \\
\hline 1 & Curcumin & $183^{\circ} \mathrm{C}$ & $181^{\circ} \mathrm{C}$ \\
\hline 2 & Piperine & $130^{\circ} \mathrm{C}$ & $129^{\circ} \mathrm{C}$ \\
\hline
\end{tabular}

\section{Solubility analysis:}

The solubility of pure drug sample of Curcumin and piperine was analyzed with various solvent and result was found to be:

Table 3: Solubility test of Curcumin and piperine

\begin{tabular}{|c|l|l|l|}
\hline S.No. & Solvent & Curcumin & Piperine \\
\hline 1 & Water & Insoluble & Insoluble \\
\hline 2 & Methanol & Soluble & Soluble \\
\hline 3 & Chloroform & Soluble & Soluble \\
\hline 4 & Petroleum ether & Insoluble & Soluble \\
\hline 6 & Acetic acid & Soluble & Soluble \\
\hline 7 & Ethanol & Soluble & Soluble \\
\hline
\end{tabular}

\section{Identification test and compatibility test by FTIR spectrophotometer:}

The sample of Curcumin and piperine was identified by FTIR spectra. The FTIR spectrum of pure drug and physical mixture show the characteristic absorption with functional group. By this study confirm the compatibility of Curcumin with excipients.

Characteristic peaks obtained are shown:

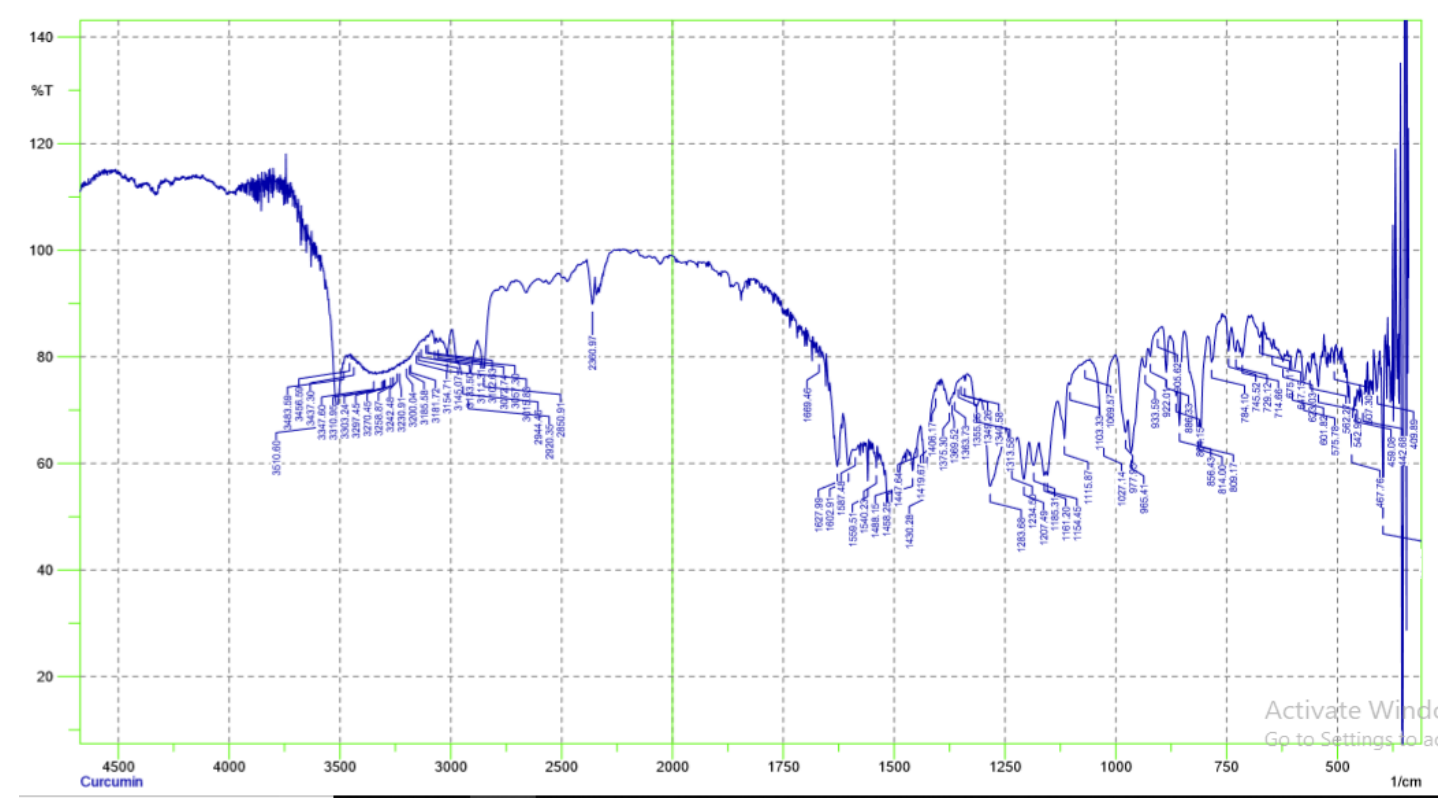

Fig. 2: FT-IR of pure Curcumin 


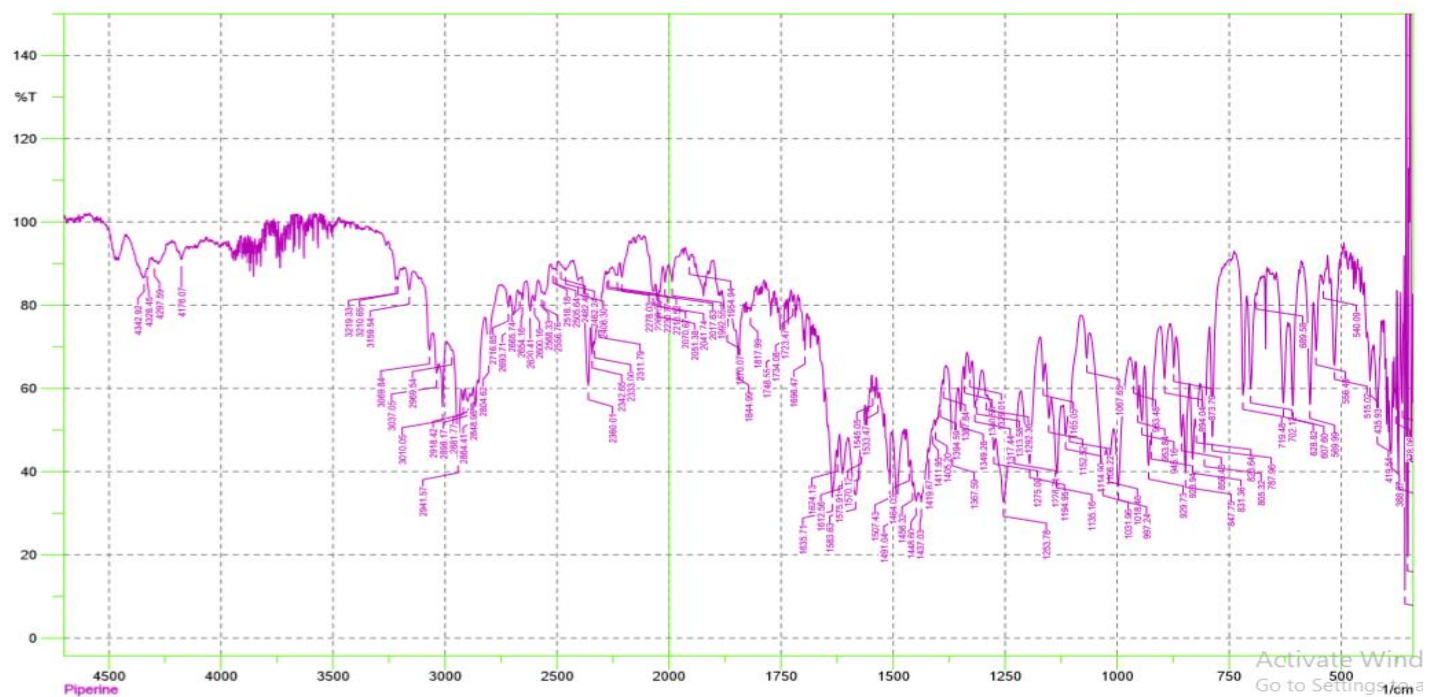

Fig. 3: FT-IR of pure piperine

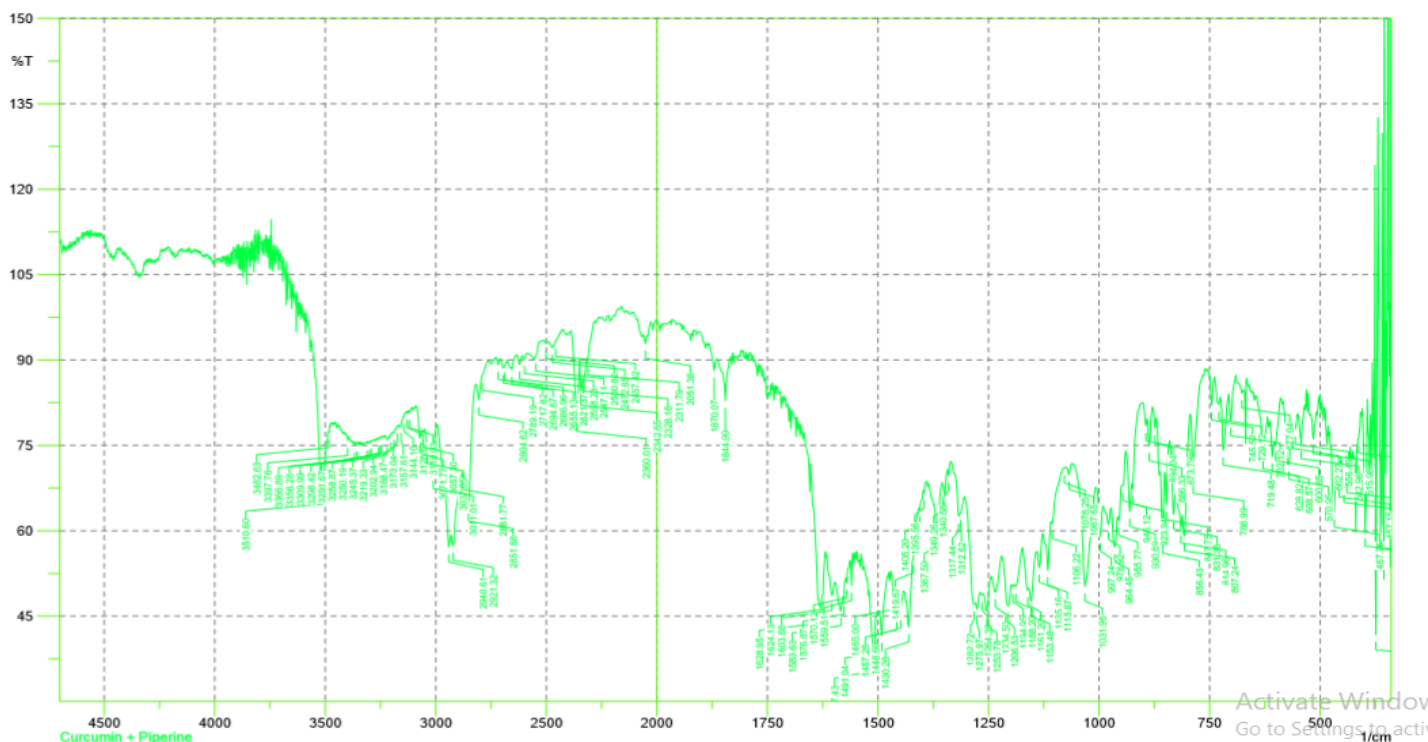

Fig. 4: FT-IR of pure Curcumin and piperine

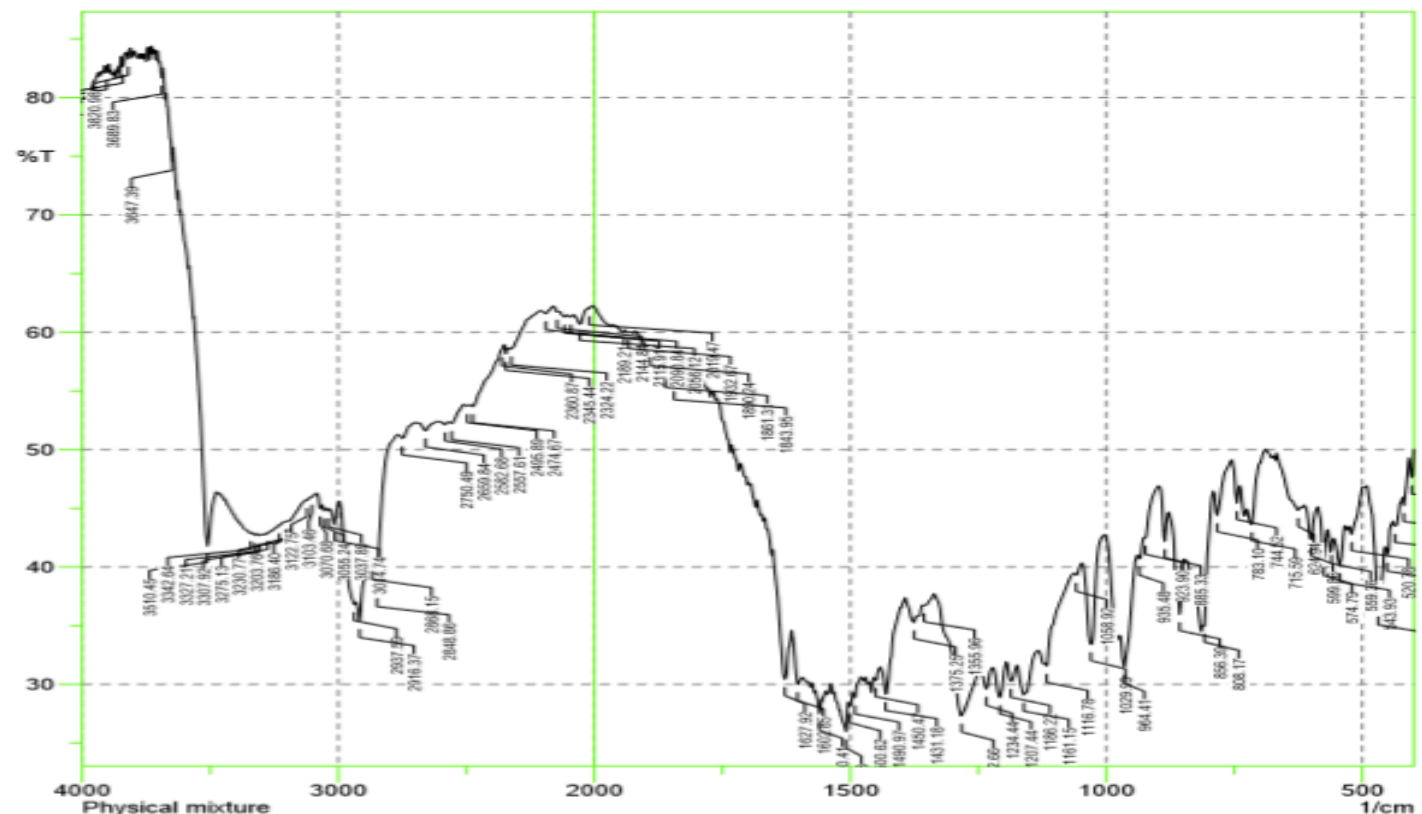

Fig. 5: FT-IR of Curcumin liposome 


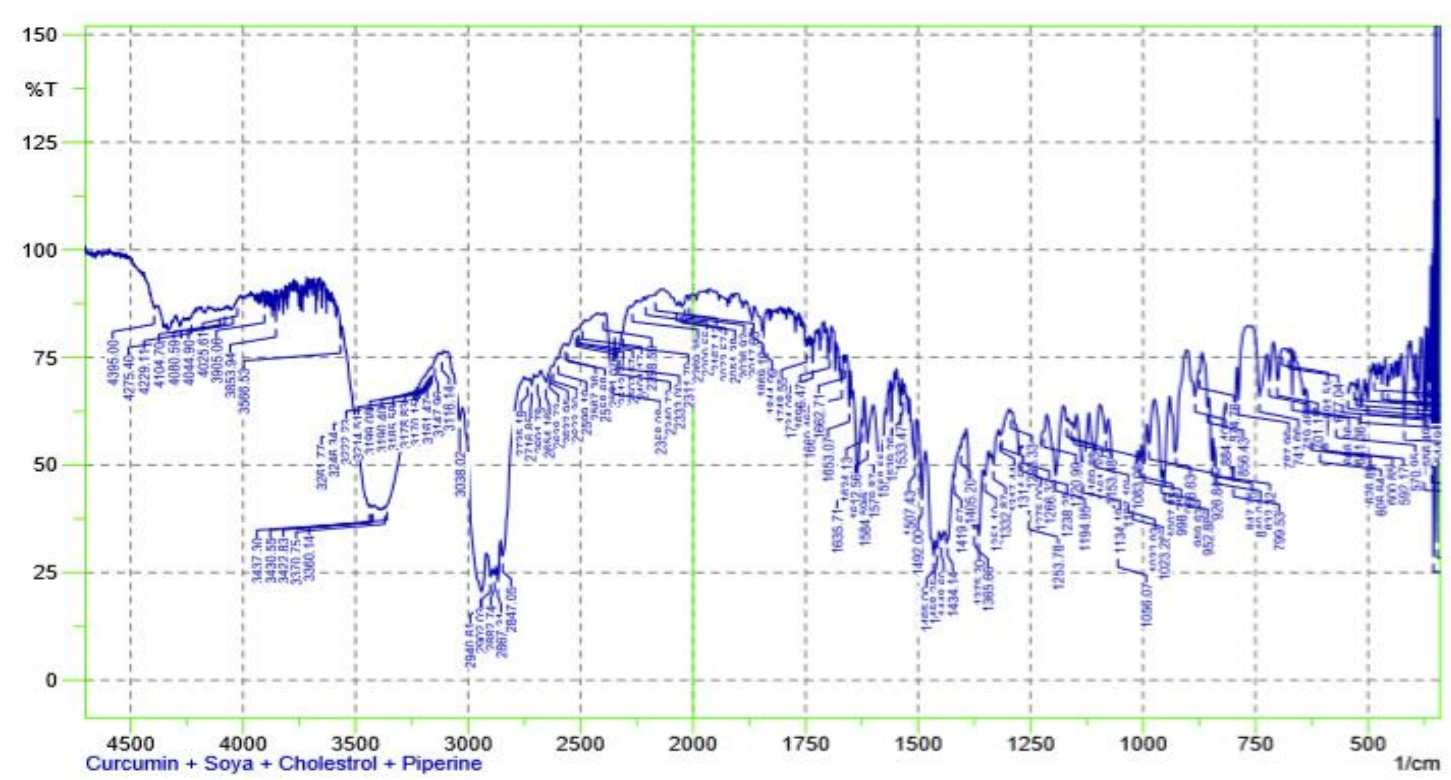

Fig. 6: FT-IR of Curcumin piperine liposome

Table 4: Characteristic peak of Curcumin

\begin{tabular}{|l|l|l|l|}
\hline S.No. & Functional group & Theoretical peak (cm-1) & Practical peak (cm-1) \\
\hline 1 & Phenolic $-\mathrm{OH}$ & 3406.54 & 3401.21 \\
\hline 2 & $-\mathrm{C}=\mathrm{O}$ & $1631.08,1604.78$ & $1629.93,1603.85$ \\
\hline 3 & Aromatic $-\mathrm{C}=\mathrm{O}$ & 1431.03 & 1428.25 \\
\hline
\end{tabular}

Table 5: Characteristic peak of piperine

\begin{tabular}{|c|c|c|c|}
\hline S.No. & Functional group & Theoretical peak (cm $\mathbf{- 1})$ & Practical peak (cm $\mathbf{- 1})$ \\
\hline 1 & Symmetric and asymmetric stretching of C=C (diene) & $1635 ; 1608$ & $1633 ; 1604.52$ \\
\hline 2 & Aromatic stretching of C=C (benzene ring) & $1608 ; 1580$ & $1601 ; 1601.25$ \\
\hline 3 & Stretching of -CO-N & 1635 & 1632.58 \\
\hline 4 & Asymmetric and symmetric, aliphatic C-H stretching & $2925 ; 2840$ & $2926 ; 2844.32$ \\
\hline 5 & CH2 bending & 1450 & 1451.59 \\
\hline 6 & Asymmetrical stretching =C-O-C & $1250 ; 1190$ & $1249 ; 1193.57$ \\
\hline 7 & C-O stretching & 930 & 931.22 \\
\hline 8 & $\begin{array}{c}\text { Out-of-plan C-H bending 1,2,4- trisubstitited phenyl } \\
\text { (two adjacent hydrogen atoms) }\end{array}$ & $850 ; 830 ; 805$ & $847 ; 829.31 ; 801.68$ \\
\hline
\end{tabular}

Table 6: Characteristic peak of mixture of pure Curcumin and piperine

\begin{tabular}{|l|l|l|l|}
\hline S.No. & Functional group & Theoretical peak (cm-1) & Practical peak (cm-1) \\
\hline 1 & Phenolic - OH & 3406.54 & 3401.21 \\
\hline 2 & Symmetric and asymmetric stretching of C=C (Diane) & $1635 ; 1608$ & $1633 ; 1604.52$ \\
\hline 3 & - C=O & $1631.08,1604.78$ & $1629.93,1603.85$ \\
\hline 4 & Aromatic stretching of C=C (benzene ring) & $1608 ; 1580$ & $1601 ; 1601.25$ \\
\hline 5 & Aromatic -C=O & 1431.03 & 1428.25 \\
\hline 6 & Stretching of -CO-N & 1635 & 1632.58 \\
\hline 7 & Asymmetric and symmetric, aliphatic C-H stretching & $2925 ; 2840$ & $2926 ; 2844.32$ \\
\hline 8 & Asymmetrical stretching =C-O-C & $1250 ; 1190$ & $1249 ; 1193.57$ \\
\hline 9 & C-O stretching & 930 & 931.22 \\
\hline 10 & $\begin{array}{l}\text { Out-of-plan C-H bending 1,2,4- trisubstitited phenyl } \\
\text { (two adjacent hydrogen atoms) }\end{array}$ & $850 ; 830 ; 805$ & $847 ; 829.31 ; 801.68$ \\
\hline
\end{tabular}

Table 7: Characteristic peak of Curcumin liposome

\begin{tabular}{|l|l|l|l|}
\hline S.No. & Functional group & Theoretical peak $\mathbf{( c m}^{-1} \mathbf{)}$ & Practical peak (cm-1) \\
\hline 1 & Phenolic $-\mathrm{OH}$ & 3406.54 & 3401.21 \\
\hline 2 & $-\mathrm{C}=\mathrm{O}$ & $1631.08,1604.78$ & $1629.93,1603.85$ \\
\hline 3 & Aromatic $-\mathrm{C}=\mathrm{O}$ & 1431.03 & 1428.25 \\
\hline
\end{tabular}


Table 8: Characteristic peak of mixture of Curcumin piperine liposome

\begin{tabular}{|l|l|l|l|}
\hline S.No. & Functional group & $\begin{array}{l}\text { Theoretical peak } \mathbf{( c m}- \\
\mathbf{1})\end{array}$ & Practical peak (cm-1) \\
\hline 1 & Phenolic -OH & 3406.54 & 3401.21 \\
\hline 2 & $\begin{array}{l}\text { Symmetric and asymmetric stretching of C=C } \\
\text { diene) }\end{array}$ & $1635 ; 1608$ & $1633 ; 1604.52$ \\
\hline 3 & $-\mathrm{C}=0$ & $1631.08,1604.78$ & $1629.93,1603.85$ \\
\hline 4 & Aromatic stretching of C=C (benzene ring) & $1608 ; 1580$ & $1601 ; 1601.25$ \\
\hline 5 & Aromatic -C=O & 1431.03 & 1428.25 \\
\hline 6 & Stretching of -CO-N & 1635 & 1632.58 \\
\hline 7 & Asymmetric and symmetric, aliphatic C-H stretching & $2925 ; 2840$ & $2926 ; 2844.32$ \\
\hline 8 & Asymmetrical stretching =C-O-C & $1250 ; 1190$ & $1249 ; 1193.57$ \\
\hline 9 & C-O stretching & 930 & 931.22 \\
\hline 10 & $\begin{array}{l}\text { Out-of-plan C-H bending 1,2,4- trisubstitited phenyl } \\
\text { (two adjacent hydrogen atoms) }\end{array}$ & $850 ; 830 ; 805$ & $847 ; 829.31 ; 801.68$ \\
\hline
\end{tabular}

\section{$\lambda$ max analysis:}

The absorption spectrum of pure drug was scanned in 200$800 \mathrm{~nm}$. The lambda max of pure Curcumin was found to be
$425 \mathrm{~nm}$ which is standard range between i.e., $421-425 \mathrm{~nm}$ and piperine was found to be $342 \mathrm{~nm}$ it is range between 341-343nm. The $\lambda \max$ analysis data show in table 9.

Table 9: Wavelength of maximum absorption of Curcumin and piperine

\begin{tabular}{|c|c|c|c|}
\hline S.No. & Drug & Theoretical $\boldsymbol{\lambda}$ max & Practically Obtain $\boldsymbol{\lambda}$ max \\
\hline 1 & Curcumin & $421-425 \mathrm{~nm}$ & $425 \mathrm{~nm}$ \\
\hline 2 & Piperine & $342 \mathrm{~nm}$ & $342 \mathrm{~nm}$ \\
\hline
\end{tabular}

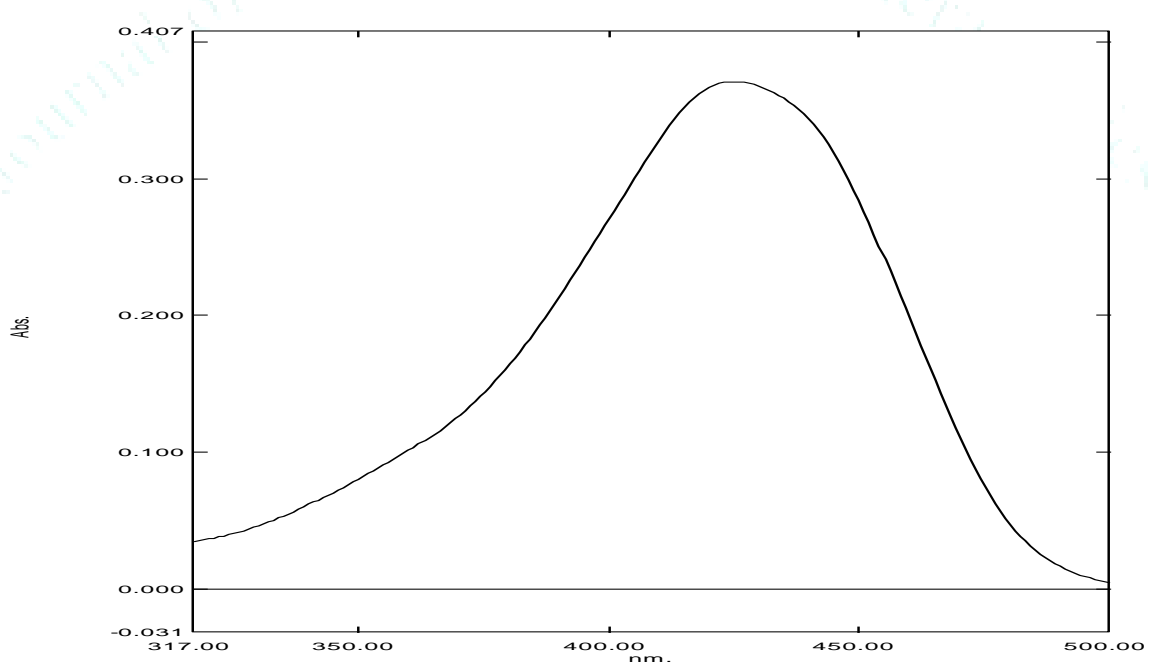

Fig. 7: Lambda max of Curcumin

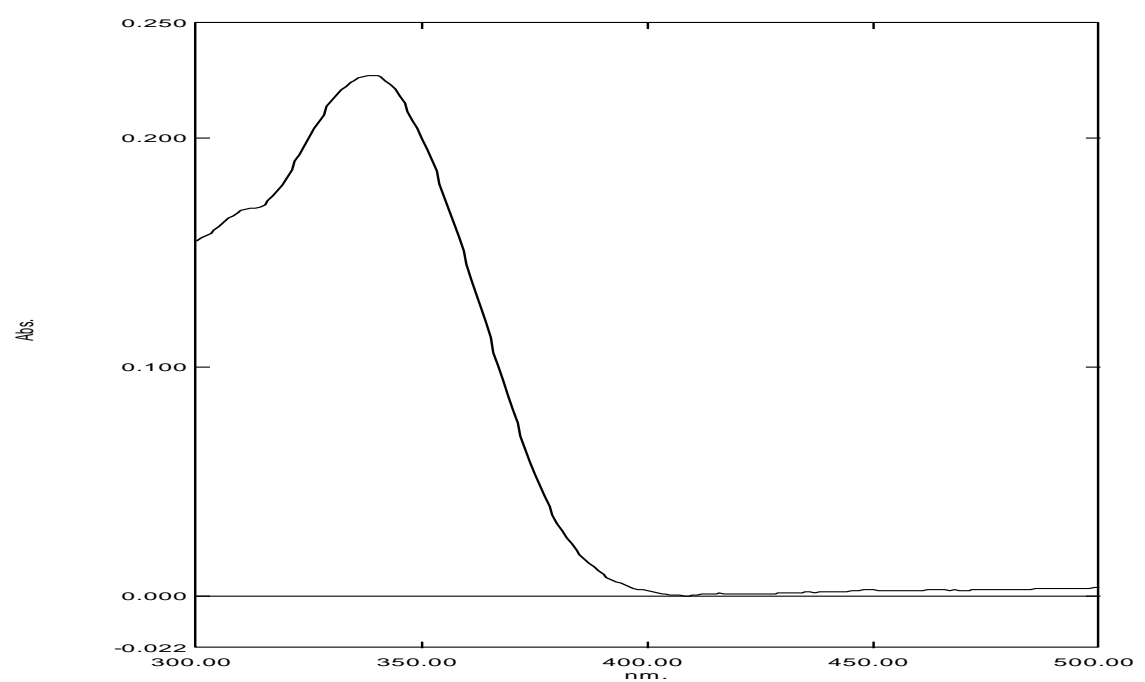

Fig. 8: Lambda max of piperine 


\section{Calibration curve of Curcumin and piperine:}

Standard calibration curve in Table no.10 and 11 show the absorbance of Curcumin and piperine at different concentration 1, 2, 34,5 , and $6 \mu \mathrm{g} / \mathrm{ml}$ and figure no. 9 and 10 show the standard curve of Curcumin at $425 \mathrm{~nm}$ and piperine at $342 \mathrm{~nm}$. The regression value was found to be 0.9953 and 0.996 .

Table 10: Absorbance of Curcumin at different concentration

\begin{tabular}{|c|c|c|}
\hline S.No. & $\begin{array}{c}\text { Concentration } \\
(\boldsymbol{\mu g} \mathbf{g} \mathbf{m l})\end{array}$ & $\begin{array}{c}\text { Absorbance of Curcumin } \\
(\mathbf{4 2 5} \mathbf{~ n m})\end{array}$ \\
\hline 1 & $1 \mu \mathrm{g} / \mathrm{ml}$ & 0.274 \\
\hline 2 & $2 \mu \mathrm{g} / \mathrm{ml}$ & 0.419 \\
\hline 3 & $3 \mu \mathrm{g} / \mathrm{ml}$ & 0.582 \\
\hline 4 & $4 \mu \mathrm{g} / \mathrm{ml}$ & 0.800 \\
\hline 5 & $5 \mu \mathrm{g} / \mathrm{ml}$ & 0.938 \\
\hline 6 & $6 \mu \mathrm{g} / \mathrm{ml}$ & 1.163 \\
\hline
\end{tabular}

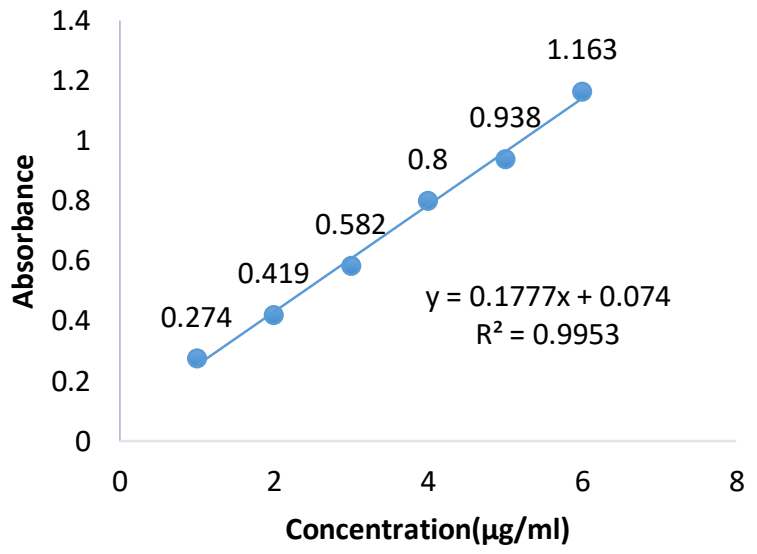

Fig. 9: Standard calibration curve of Curcumin
Table 11 Absorbance of piperine at different concentration

\begin{tabular}{|c|c|c|}
\hline S.No. & $\begin{array}{c}\text { Concentration } \\
(\boldsymbol{\mu g} / \mathbf{m l})\end{array}$ & $\begin{array}{c}\text { Absorbance of piperine } \\
(\mathbf{3 4 2} \mathbf{~ n m})\end{array}$ \\
\hline 1 & $1 \mu \mathrm{g} / \mathrm{ml}$ & 0.140 \\
\hline 2 & $2 \mu \mathrm{g} / \mathrm{ml}$ & 0.274 \\
\hline 3 & $3 \mu \mathrm{g} / \mathrm{ml}$ & 0.389 \\
\hline 4 & $4 \mu \mathrm{g} / \mathrm{ml}$ & 0.565 \\
\hline 5 & $5 \mu \mathrm{g} / \mathrm{ml}$ & 0.664 \\
\hline 6 & $6 \mu \mathrm{g} / \mathrm{ml}$ & 0.834 \\
\hline
\end{tabular}

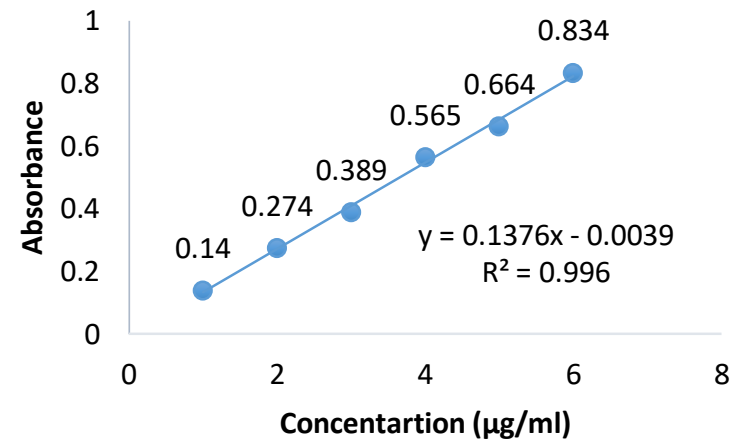

Fig. 10: Standard calibration curve of piperine

\section{Evaluation of final formulation}

\section{Mean particle size and Polydispersity Index:}

Mean particle size of all liposome formulation (F1-F5) is found in range between 800-1000. By the result obtain of mean particle size it can conclude that the all liposomes are a large unilamellarvesicle types liposome. PDI and Mean particle size data show in table 12 and figure 11-15.

Table 12: Mean Particle Size and Polydispersity Index of all liposome formulation

\begin{tabular}{|c|c|c|}
\hline Formulation code & Mean particle size (nm) & Polydispersity Index \\
\hline F1 & 819.5 & 0.841 \\
\hline F2 & 1031 & 0.855 \\
\hline F3 & 1081 & 1 \\
\hline F4 & 848 & 0.858 \\
\hline F5 & 931 & 0.909 \\
\hline
\end{tabular}

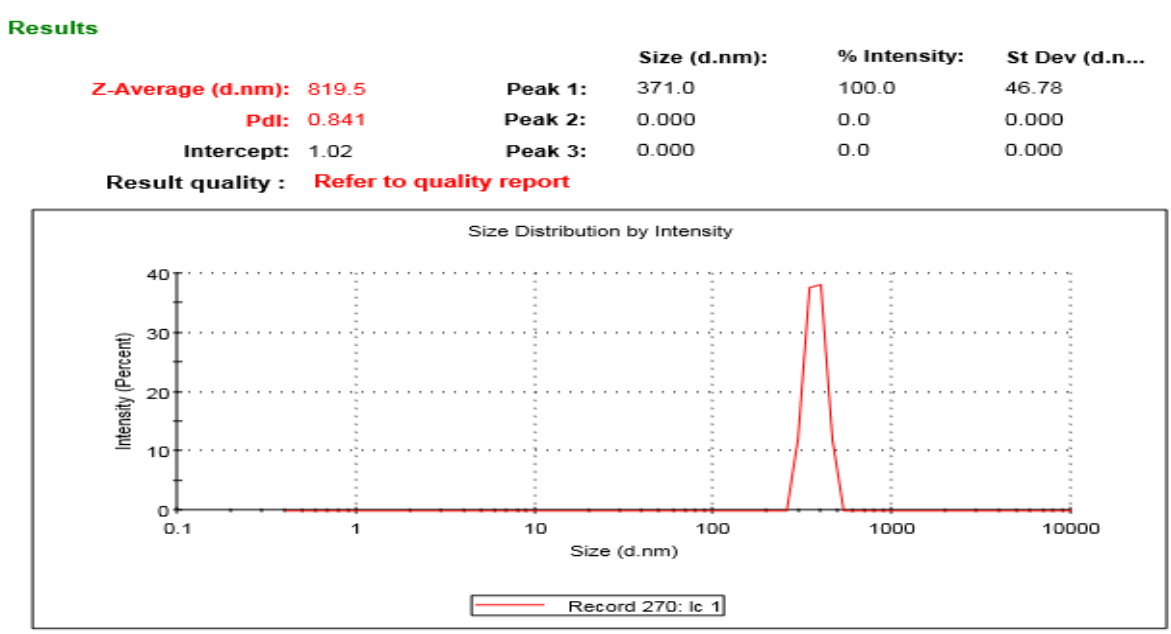

Fig. 11: Graph of mean particle size and polydispersity index (F1) 
Results

$\begin{array}{rlllll} & & & \text { Size (d.nm): } & \% \text { Intensity: } & \text { St Dev (d.n... } \\ \text { Z-Average (d.nm): } & 1031 & \text { Peak 1: } & 477.9 & 100.0 & 45.76 \\ \text { Pdl: } & 0.855 & \text { Peak 2: } & 0.000 & 0.0 & 0.000 \\ \text { Intercept: } & 0.995 & \text { Peak 3: } & 0.000 & 0.0 & 0.000\end{array}$

Result quality : Refer to quality report

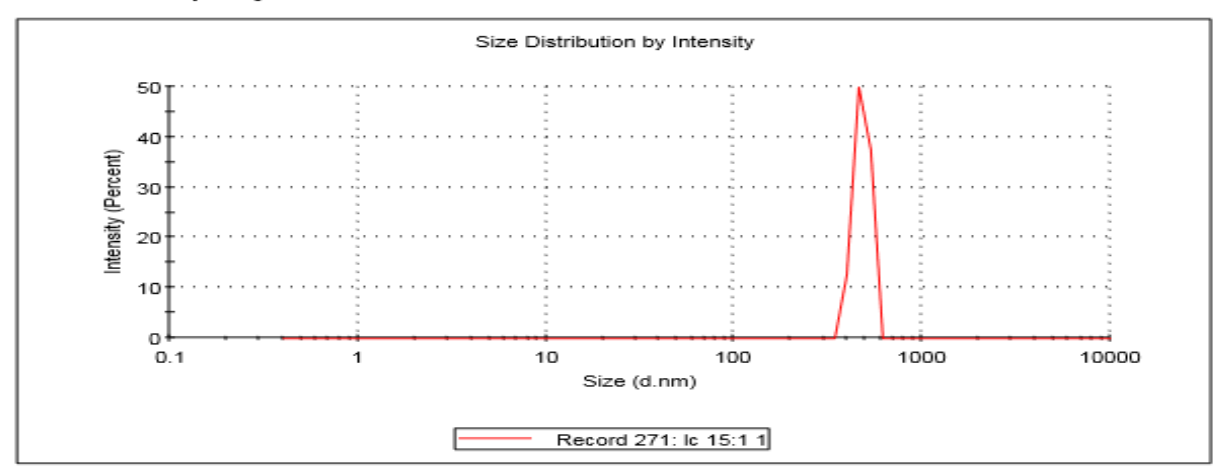

Fig. 12: Graph of mean particle size and polydispersity index (F2)

Results

$\begin{array}{rlllll} & & & \text { Size (d.nm): } & \% \text { Intensity: } & \text { St Dev (d.n... } \\ \text { Z-Average (d.nm): } & 1081 & \text { Peak 1: } & 242.4 & 100.0 & 16.72 \\ \text { Pdl: } & 1.000 & \text { Peak 2: } & 0.000 & 0.0 & 0.000 \\ \text { Intercept: } & 1.13 & \text { Peak 3: } & 0.000 & 0.0 & 0.000\end{array}$

Result quality : Refer to quality report

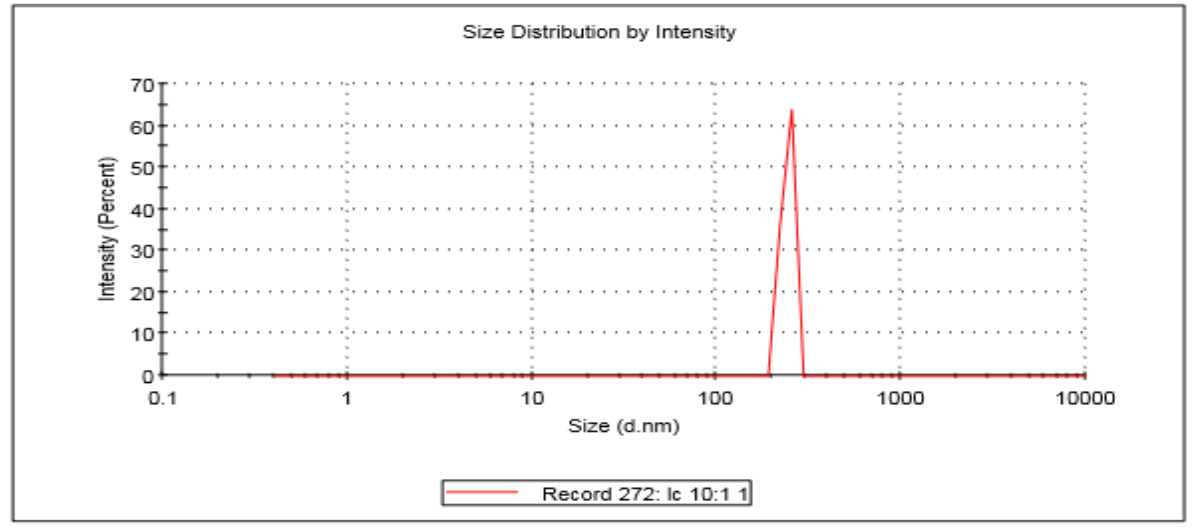

Fig. 13: Graph of mean particle size and polydispersity index (F3)

Results

$\begin{array}{rlllll} & & & \text { Size (d.nm): } & \text { \% Intensity: } & \text { St Dev (d.n... } \\ \text { Z-Average (d.nm): } & 848.6 & \text { Peak 1: } & 456.5 & 89.5 & 79.13 \\ \text { Pdl: } & 0.858 & \text { Peak 2: } & 0.8843 & 10.5 & 0.06557 \\ \text { Intercept: } & 0.953 & \text { Peak 3: } & 0.000 & 0.0 & 0.000\end{array}$

Result quality : Refer to quality report

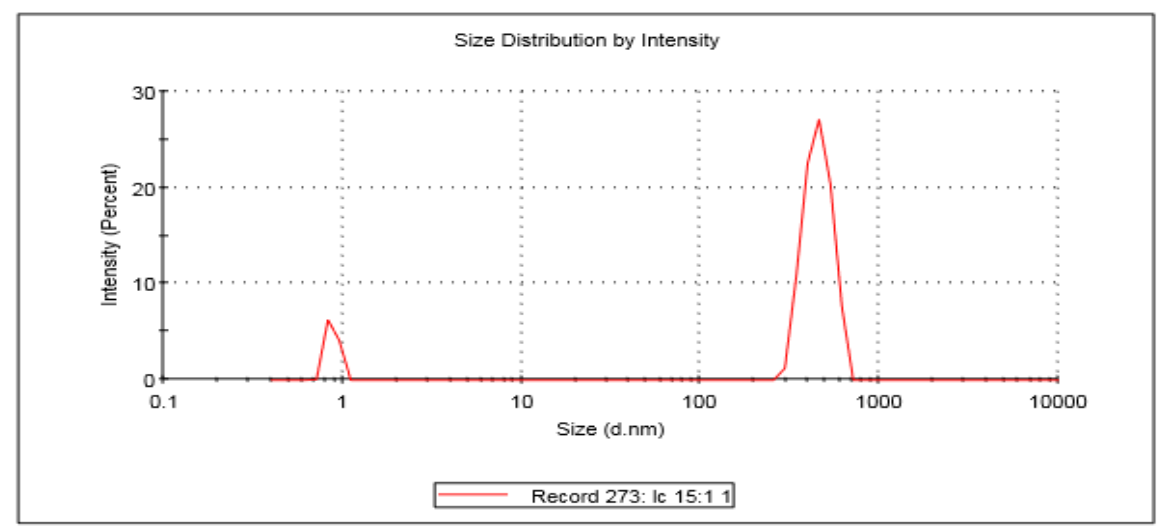

Fig. 14: Graph of mean particle size and polydispersity index (F4) 


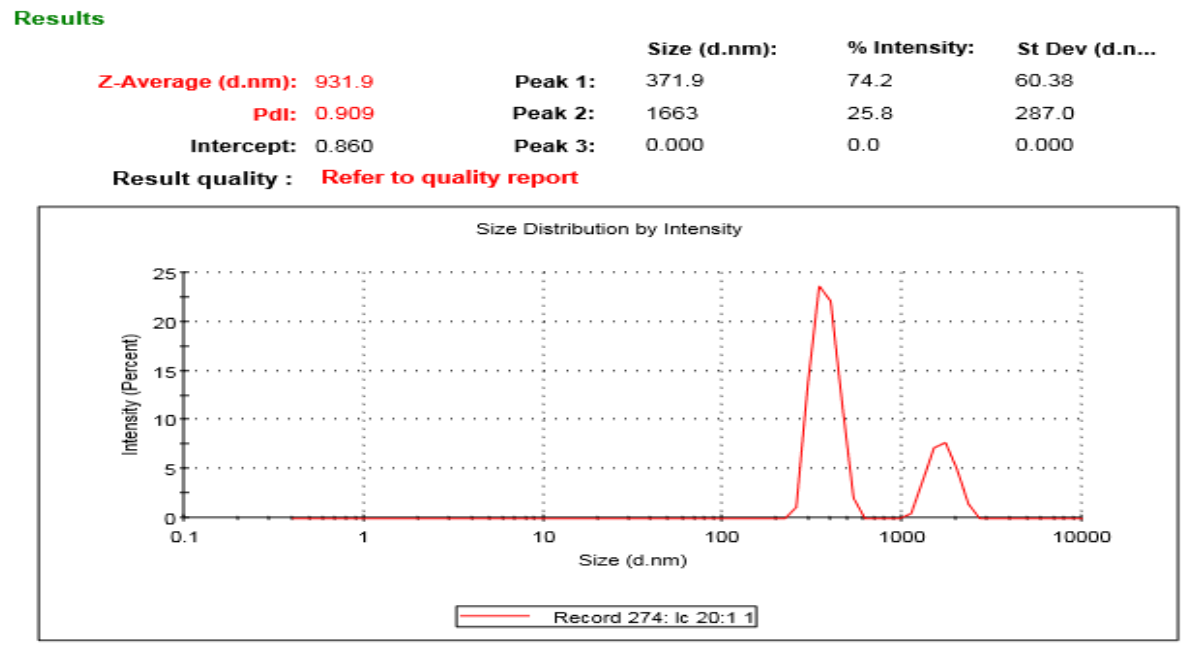

Fig. 15: Graph of mean particle size and polydispersity index (F5)

\section{Zeta potential:}

The stability of liposome is directly related to the charge present in mobile surface, which is termed as zeta potential. Zeta potential was determining by the zetasizer. The zeta potential of liposomes formulation F1-F5 was found in range between -1 to $-29 \mathrm{mV}$. By zeta potential study its conform that the all formulation was stable. Surface charge data show in table 13:

Table 13: Zeta potential of liposome formulation

\begin{tabular}{|c|c|}
\hline Formulation code & Zeta potential (mV) \\
\hline F1 & $-1.18 \pm 1.6$ \\
\hline F2 & $-9.73 \pm 25$ \\
\hline F3 & $-17.10 \pm 90$ \\
\hline F4 & $-21.32 \pm 5.8$ \\
\hline F5 & $-29.6 \pm 6.0$ \\
\hline
\end{tabular}

\section{Drug encapsulation efficiency:}

The result of encapsulation efficiency of all formulation was found to be almost similar. Also it can be observed that, encapsulation efficiency was increase with increasing particle size. Table 14 and figure 16 was shown the drug encapsulation efficiency of liposome.

Table 14: Drug encapsulation efficiency of liposome formulation

\begin{tabular}{|c|c|c|}
\hline Drug & Formulations & $\begin{array}{c}\text { Encapsulation efficiency } \\
\text { (\%) }\end{array}$ \\
\hline 1 & F1 & $59 \%$ \\
\hline 2 & F2 & $65 \%$ \\
\hline 3 & F3 & $67 \%$ \\
\hline 4 & F4 & $61 \%$ \\
\hline 5 & F5 & $63 \%$ \\
\hline
\end{tabular}

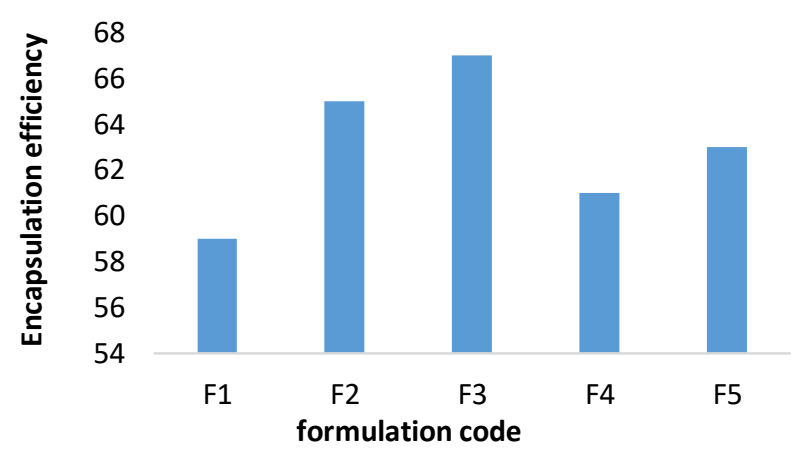

Fig. 16: Graph of drug encapsulation efficiency of liposome formulation

In-vitro drug release studies:

In-vitro drug release of Curcumin liposome and curcuminpiperine liposome formulation was carried out by using dialysis membrane in $7.4 \mathrm{pH}$ phosphate buffer for $12 \mathrm{hrs}$. and drug release varied in range between $70-77 \%$, and all formulation are follow sustained release thus they reduce metabolism, good absorption rate which improve bioavailability of drug. The good cumulative drug release existed in all batches. After application of data treatment to dissolution, release behavior follows zero order kinetic. In vitro drug release profile data show in table 15 and 16 and figure 17.

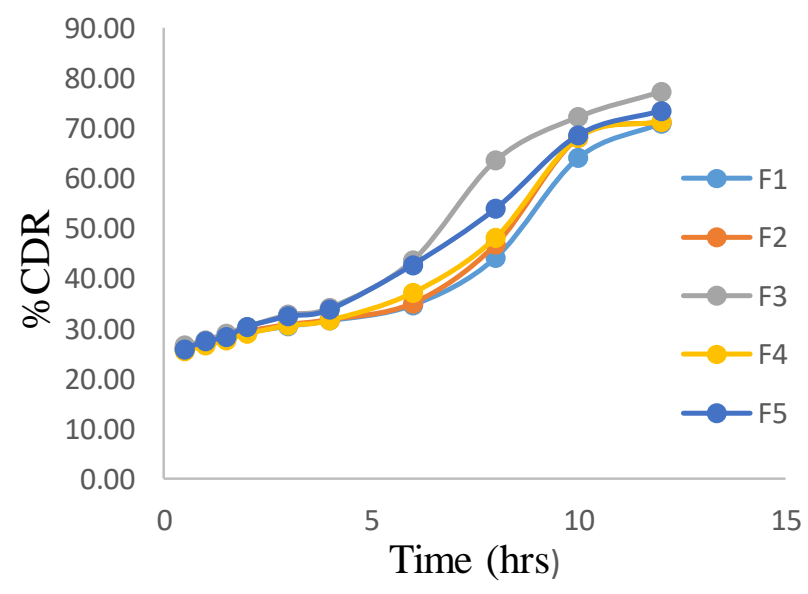

Fig. 17 In vitro drug release profile of liposome formulation 
Table 15: Percentage cumulative drug release profile of liposome formulation

\begin{tabular}{|c|c|c|c|c|c|c|}
\hline \multirow{2}{*}{ S.No. } & \multirow{2}{*}{ Time (hr.) } & \multicolumn{5}{|c|}{ \%CDR } \\
\cline { 3 - 7 } & & F1 & F2 & F3 & F4 & F5 \\
\hline 1 & 0.5 & 25.85 & 26.23 & 26.60 & 25.55 & 25.88 \\
\hline 2 & 1 & 27.01 & 27.29 & 27.67 & 26.59 & 27.52 \\
\hline 3 & 1.5 & 27.94 & 28.19 & 29.02 & 27.68 & 28.29 \\
\hline 4 & 2 & 29.18 & 29.43 & 30.35 & 28.95 & 30.35 \\
\hline 5 & 3 & 30.47 & 30.79 & 32.75 & 30.61 & 32.44 \\
\hline 6 & 4 & 31.57 & 31.79 & 34.11 & 31.64 & 33.79 \\
\hline 7 & 6 & 34.67 & 35.05 & 43.56 & 37.12 & 42.70 \\
\hline 8 & 8 & 44.12 & 46.74 & 63.50 & 48.12 & 53.90 \\
\hline 9 & 10 & 64.06 & 68.07 & 72.23 & 68.09 & 68.63 \\
\hline 10 & 12 & 70.96 & 71.28 & 77.24 & 71.30 & 73.47 \\
\hline
\end{tabular}

Table 16: Best Fit Model for all formulations

\begin{tabular}{|c|c|c|c|c|c|}
\hline \multirow{2}{*}{ Formulations } & Zero order & First order & $\begin{array}{c}\text { Higuchi } \\
\text { matrix }\end{array}$ & Peppas plot & Best fit Model \\
\cline { 2 - 6 } & $\mathbf{R}^{\mathbf{2}}$ & $\mathbf{R}^{\mathbf{2}}$ & $\mathbf{R}^{\mathbf{2}}$ & $\mathbf{R}^{\mathbf{2}}$ & \\
\hline F1 & 0.9078 & 0.7441 & 0.8062 & 0.7362 & Zero order \\
\hline F2 & 0.9083 & 0.7519 & 0.8105 & 0.7361 & Zero order \\
\hline F3 & 0.964 & 0.8486 & 0.8973 & 0.8226 & Zero order \\
\hline F4 & 0.9326 & 0.7809 & 0.8425 & 0.7745 & Zero order \\
\hline F5 & 0.9726 & 0.8409 & 0.9013 & 0.8374 & Zero order \\
\hline
\end{tabular}

\section{In vivo study:}

In vivo bioavailability study demonstrated the signification improvement of curcumin-piperine loaded liposome as compared to pure Curcumin. Liposome Curcumin and liposome Curcumin-pure piperine formulation were show increased bioavailability but not as much as curcumin-piperine liposome formulation has presented.
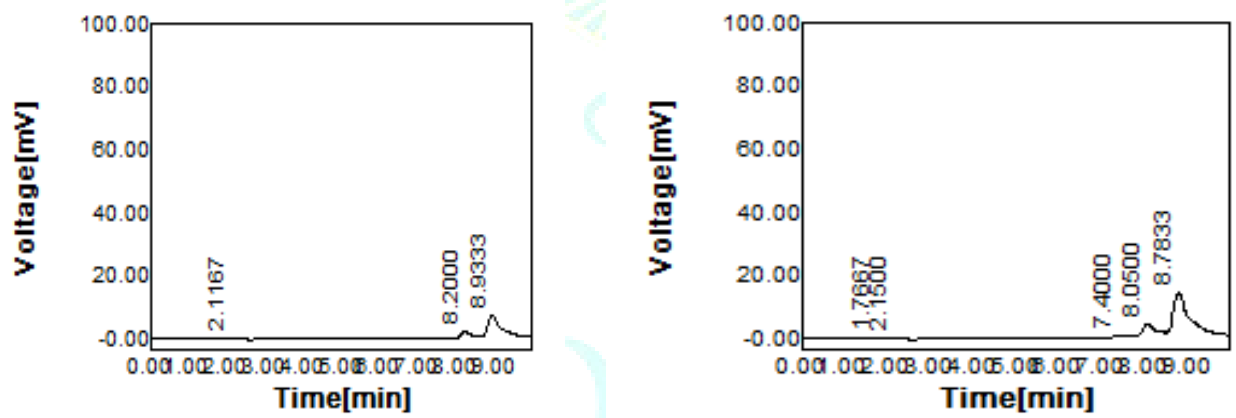

(a)

(b)
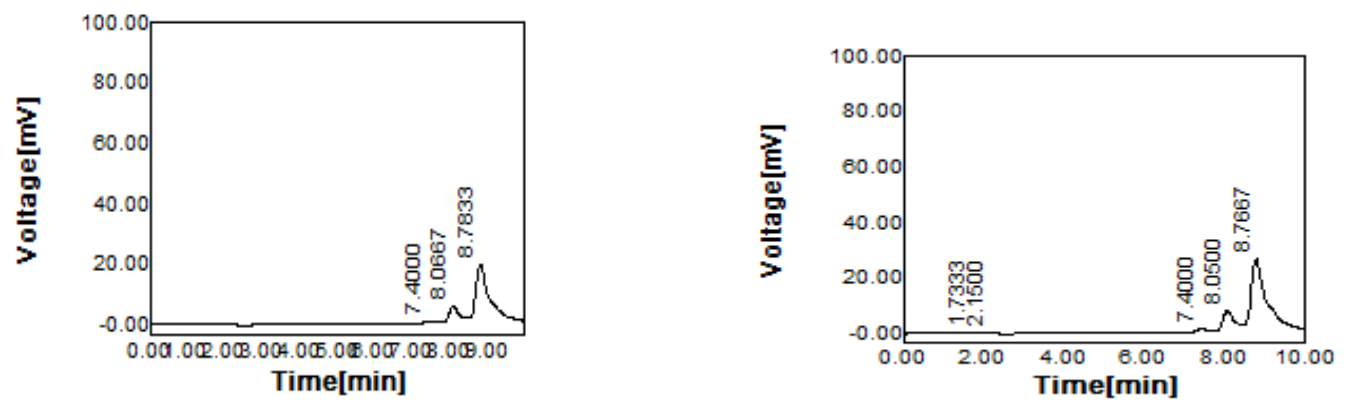

(c)

(d)

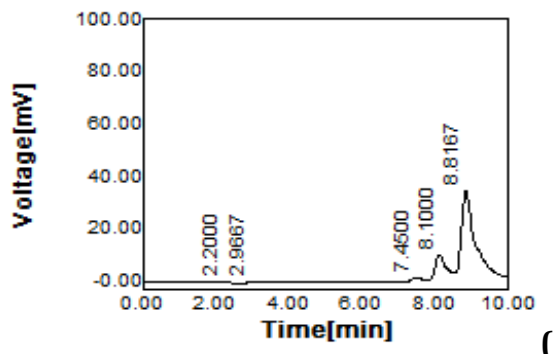

(e)

Fig. 18: Standard calibration curve of Curcumin by HPLC at different concentration 2(a), 4(b), 6(c), 8(d), 10 $\mu \mathrm{m} / \mathrm{ml}(\mathrm{e})$ 
Table 17: Absorbance of Curcumin at different concentration by HPLC

\begin{tabular}{|c|c|c|}
\hline S.No. & Concentration $(\boldsymbol{\mu g} / \mathbf{m l})$ & Peak area value \\
\hline 1 & $2 \mu \mathrm{g} / \mathrm{ml}$ & 177.133 \\
\hline 2 & $4 \mu \mathrm{g} / \mathrm{ml}$ & 353.2281 \\
\hline 3 & $6 \mu \mathrm{g} / \mathrm{ml}$ & 488.4909 \\
\hline 4 & $8 \mu \mathrm{g} / \mathrm{ml}$ & 673.9156 \\
\hline 5 & $10 \mu \mathrm{g} / \mathrm{ml}$ & 860.4714 \\
\hline
\end{tabular}

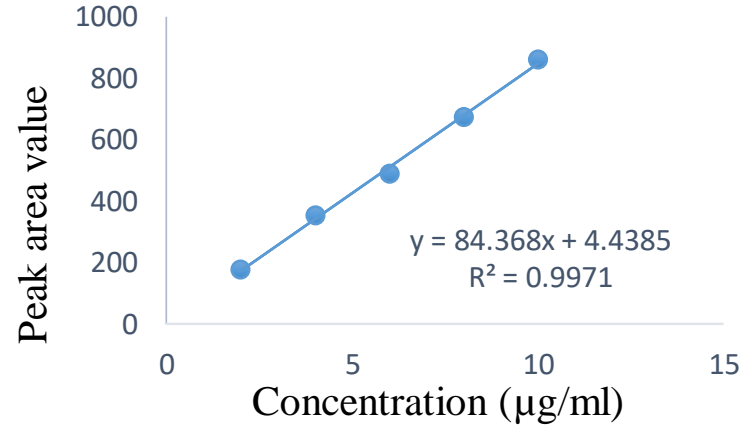

Fig. 19: Standard graph of Curcumin by HPLC

Table 18: Pharmacokinetic parameters

\begin{tabular}{|c|c|c|c|c|}
\hline Parameters & $\begin{array}{c}\text { Curcumin } \\
\text { liposome } \\
\text { formulation }\end{array}$ & $\begin{array}{c}\text { Curcumin liposome } \\
\text { + pure piperine }\end{array}$ & $\begin{array}{c}\text { Curcumin: piperine } \\
\text { liposome }\end{array}$ & $\begin{array}{c}\text { Pure } \\
\text { Curcumin }\end{array}$ \\
\hline $\mathrm{C}_{\max }(\mu \mathrm{g} / \mathrm{ml})$ & 3.450 & 10.342 & 15.096 & 1.861 \\
\hline $\mathrm{T}_{\max }(\mathrm{h})$ & 6 & 6 & 6.6 & 3 \\
\hline$A U C_{0-24}(\mu \mathrm{g} / \mathrm{ml} / \mathrm{h})$ & 30.096 & 70.325 & 200.145 & 13.01 \\
\hline $\mathrm{MRT}$ & 13.46 & 15.22 & 19.221 & 0.0733 \\
\hline $\mathrm{K}_{\mathrm{el}}$ & 0.0725 & 0.0652 & 0.0325 & 29.123 \\
\hline
\end{tabular}

\section{CONCLUSION:}

In the present study, an attempt has been made to develop liposomal delivery system for Curcumin. This study indicates successfully preparation of Curcumin loaded liposome by the thin film hydration method. Preformulation studies were performed for identification of drug i.e. physical appearance, melting point, solubility study etc. which deals with the I.P. FT-IR study confirm the compatibility of Curcumin with excipients which is used in liposome preparation. Phospholipids i.e. soy lecithin, cholesterol used as a carrier for preparation of Curcumin and piperine at different ratio (F1-F5) by thin film hydration method. The all liposome formulations (F1-F5) were evaluated for mean particle size, polydispersity index, zeta potential, encapsulation efficiency and drug release. Bioavailability was also determined on rat. The mean particle size was found in the range between 800 1100 that indicate liposome are large unilamellar vesicle. By zeta potential study it was confirmed that the all formulation were stable. The encapsulation efficiency of all liposome formulation are varied between 59-67\%. In vitro drug release was analyze in $7.4 \mathrm{pH}$ phosphate buffer, the maximum \%CDR observed at the $12 \mathrm{hrs}$. and drug release varied in range between $70-77 \%$, and formulation are follow sustained release thus they reduce metabolism, good absorption rate which improve bioavailability of drug. The good CDR existed in all batches. After application of data treatment to dissolution, release behavior follows zero order kinetic. Curcumin-piperine ratio $(10: 1$, F3) is selected as optimize formulation based on the highest entrapment efficiency (67\%), \% CDR (77.24\%), particle size (1081), polydispersity index (1) and zeta potential (-17.10). Dissolution profile and In vivo bioavailability study demonstrated the signification improvement of curcuminpiperine loaded liposome as compared to pure Curcumin. Liposome Curcumin and liposome containing curcuminpiperine formulation were show increased bioavailability but not as much as curcumin-piperine liposome formulation had shown. Based on the observations, it can be concluded that the drug delivery system of Curcumin and curcuminpiperine liposome has increase absorption and reduce metabolism in biological system which can improve bioavailability of drug.

\section{REFERENCES:}

1. Nasri H, Sahinfard N, Rafieian M, Rafieian S, Shirzad M, Rafieian-Kopaei M. Turmeric: A spice with multifunctional medicinal properties. Journal of HerbMed Pharmacology. 2014;3.

2. Methane D, Yellow T. Chemoprevention Branch and Agent Development Committee t. 85(1 996).

3. Wilken R, Veena MS, Wang MB, Srivatsan ES. Curcumin: A review of anti-cancer properties and therapeutic activity in head and neck squamous cell carcinoma. Molecular cancer. 2011 Dec;10(1):12.

4. Zern TL, Fernandez ML. Recent Advances in Nutritional Sciences Cardioprotective Effects of Dietary. 2018;(June):2291-

5. Hewlings SJ, Kalman DS. Curcumin: a review of its' effects on human health. Foods. 2017 Oct 22;6(10):92.

6. Metzler M, Pfeiffer E, Schulz SI, Dempe JS. Curcumin uptake and metabolism. Biofactors. 2013 Jan 1;39(1):14-20.

7. Suresh D, Srinivasan K. Studies on the in vitro absorption of spice principles-curcumin, capsaicin and piperine in rat intestines. Food and chemical toxicology. 2007 Aug 1;45(8):1437-42.

8. Strimpakos AS, Sharma RA. Curcumin: preventive and therapeutic properties in laboratory studies and clinical trials. Antioxidants \& redox signaling. 2008 Mar 1;10(3):511-46.

9. Nelson KM, Dahlin JL, Bisson J, Graham J, Pauli GF, Walters MA. The essential medicinal chemistry of curcumin: miniperspective. Journal of medicinal chemistry. 2017 Jan 11;60(5):1620-37.

10. Priyadarsini KI. The Chemistry of Curcumin: From Extraction to Therapeutic Agent. 2014;20091-112.

11. Prasad S, Tyagi AK, Aggarwal BB. Recent developments in delivery, bioavailability, absorption and metabolism of curcumin: The golden pigment from golden spice. Cancer Res Treat. 2014;46(1):2-18.

12. Anand P, Kunnumakkara AB, Newman RA, Aggarwal BB. Bioavailability of curcumin: problems and promises. Molecular pharmaceutics. 2007 Nov 14;4(6):807-18. 
13. Liu W, Zhai Y, Heng X, Che FY, Chen W, Sun D, Zhai G. Oral bioavailability of curcumin: problems and advancements. Journal of drug targeting. 2016 Sep 13;24(8):694-702.

14. Hoehle SI, Pfeiffer E, Sólyom AM, Metzler M. Metabolism of curcuminoids in tissue slices and subcellular fractions from rat liver. Journal of agricultural and food chemistry. 2006 Feb 8;54(3):756-64.

15. Ireson CR, Jones DJ, Orr S, Coughtrie MW, Boocock DJ, Williams ML, Farmer PB, Steward WP, Gescher AJ. Metabolism of the cancer chemopreventive agent curcumin in human and rat intestine. Cancer Epidemiology and Prevention Biomarkers. 2002 Jan 1;11(1):105-11.

16. Indian pharmacopiea, Year 2007, Volume-I, Page no.-2040.

17. Shukla J. Parameters of preformulation studies by : $\mathrm{Dr}$. Jill Shukla. 2017;(September).

18. Reddy CS, Khan KK, Nagaraja C. A Review on the Determination of Melting Point Measurement System. International Journal of Advanced Research in Electrical, Electronics and Instrumentation Engineering. 2016;5(2):9759.

19. Gorgani L, Mohammadi M, Najafpour GD, Nikzad M. Piperine-the bioactive compound of black pepper: from isolation to medicinal formulations. Comprehensive Reviews in Food Science and Food Safety. 2017 Jan;16(1):124-40.

20. Modasiya MK, Patel VM, Patel VM. International journal of pharmacy \& life sciences. Int. J. of Pharm. \& Life Sci.(IJPLS). 2012 Mar;3(3):1490-7.

21. Kim HJ, Kim DJ, Karthick SN, Hemalatha KV, Raj CJ, Ok S, Choe Y. Curcumin dye extracted from Curcuma longa L. used as sensitizers for efficient dye-sensitized solar cells. International Journal of Electrochemical Science. 2013 Jun 1;8(6):8320-8.

22. Pawar H, Karde M, Mundle N, Jadhav P, Mehra K Phytochemical evaluation and curcumin content determination of turmeric rhizomes collected from Bhandara District of Maharashtra (India). Med. Chem. 2014;4(8):58891.

23. Hazra K, Kumar R, Sarkar BK, Chowdary YA, Devgan M, Ramaiah M. Uv-Visible Spectrophotometric estimation of curcumin in Nanoformulation. International Journal of Pharmacognosy. 2015;2(3):127-30.

24. Lettre DP, Singh NK, Kumar P, Gupta DK, Singh S. UVspectrophotometric method development for estimation of piperine in Chitrakadi Vati. 2011;3(3):178-82.

25. Holkar VV, Nirmal DR, Mistry SK.Development and validation of uv spectrophotometric method for the estimation of curcumin in bulk and pharmaceutical formulation.

26. Sharma K, Agrawal SS, Gupta M. Development and Validation of UV spectrophotometric method for the estimation of Curcumin in Bulk Drug and Pharmaceutical Dosage Forms. Int. J. Drug Dev. Res. 2012 Apr;4(2):375-80.

27. June M. in Pharmaceutical and Nano Sciences,Formulation and in vitro evaluation of liposomes loaded with. 2015;4(3):16274.

28. Labhasetwar V, Mohan MS, Dorle AK. A study on zeta potential and dielectric constant of liposomes. Journal of microencapsulation. 1994 Jan 1;11(6):663-8.

29. Smith MC, Crist RM, Clogston JD, McNeil SE. Zeta potential: a case study of cationic, anionic, and neutral liposomes. Analytical and bioanalytical chemistry. 2017 Sep 1;409(24):5779-87.

30. Shashi K, Satinder K, Bharat P. a Complete Review on : Liposomes Upon Composition and. Int Res J Pharm. 2012;3(7):10-6.

31. Roy A, Saha S, Choudhury A, Bahadur S. Bioenhancement of Curcumin by Combined Approaches of Adjuvants and Liposomal Fabrication. Asian journal of pharmaceutics. 2016 Oct $1 ; 10(4)$ :S688-92.

32. Chen Z. Silica-coated flexible liposomes as a nanohybrid delivery system for enhanced oral bioavailability of curcumin. International Journal of Nanomedicine. 2012;5995-6002.

33. Kumar A, Badde S, Kamble R, Pokharkar VB. Development and characterization of liposomal drug delivery system for nimesulide. Int J Pharm Pharm Sci. 2010;2(Suppl 4):87-9.

34. Chang MT, Tsai TR, Lee CY, Wei YS, Chen YJ, Chen CR, Tzen JT. Elevating bioavailability of curcumin via encapsulation with a novel formulation of artificial oil bodies. Journal of agricultural and food chemistry. 2013 Sep 26;61(40):9666-71.

35. Li J, Jiang Y, Wen J, Fan G, Wu Y, Zhang C. A rapid and simple HPLC method for the determination of curcumin in rat plasma: assay development, validation and application to a pharmacokinetic study of curcumin liposome. Biomedical chromatography. 2009 Nov;23(11):1201-7.

36. Pawar YB, Purohit H, Raghavendra G, Munjal B, Lale S V, Patel $\mathrm{SB}$, et al. Novel lipid based oral formulation of curcumin : Development and optimization by design of experiments approach. Int J Pharm [Internet]. 2012;436(1-2):617-23. Available http://dx.doi.org/10.1016/j.ijpharm.2012.07.031

37. Fonseca-santos B. Nanotechnology-based drug delivery systems for the treatment of Alzheimer' $s$ disease. Int J Nanomedicine. 2015;4981-5003. 